\title{
Geotechnical Properties and Application of Lime Modified Phosphogypsum Waste
}

\author{
Tebogo MASHIFANA ${ }^{1,2}{ }^{*}$, Felix Ndubisi OKONTA ${ }^{1}$, Freeman NTULI $^{2}$ \\ ${ }^{1}$ Department of Civil Engineering Sciences, University of Johannesburg, P.O. Box 524, Auckland Park 2006, \\ Johannesburg, South Africa \\ ${ }^{2}$ Department of Chemical Engineering, University of Johannesburg, P.O. Box 17011, Doornfontein 2028, Johannesburg, \\ South Africa
}

crossref http://dx.doi.org/10.5755/j01.ms.24.3.18232

Received 24 May 2017; accepted 16 October 2017

\begin{abstract}
Residual deposits of Phosphogypsum are readily available in large quantities in South Africa and currently are landfilled or pumped into the sea, as there are limitations to engineering applications due to the radionuclides content. In this study, mild acid treated residual phosphogypsum was stabilized with Lime Fly Ash (LFA) binder, and the geotechnical properties and changes in phosphogypsum radioactivity were evaluated. Part of the LFA binder were replaced with basic oxygen slag (BOG) and the properties of the LFA-BOG composite were also evaluated. Citric acid as a reducing reagent was effective in reducing the radionuclides in the residual phosphogypsum and stabilization of acid treated phosphogypsum with lime fly ash (LFA) improved the Unconfined Compression Strength (UCS). In particular composites containing $50 \%$ PG mobilized UCS of $1.08 \mathrm{MPa}$ and optimum replacement of $30 \%$ of the LFA with BOF slag further improved the strength to 3.2 MPa. The final composites met the requirements of South African Roads (TRH4, 1996) specification and have equivalent strength values as C1-C4 materials and fit criteria for subbbase in terms of strength durability, and are also applicable for masonry bricks production in accordance with SANS 1215.

Keywords: phosphogypsum, basic oxygen slag, unconfined compressive strength.
\end{abstract}

\section{INTRODUCTION}

In large volumes of materials considered as wastes or by-products are generated by numerous industrial activities, most are disposed into sensitive environment and thus the need for remediation. Often these wastes material have no possibility of reuse due to low economic value for the companies that generate them and end up being landfilled. Phosphogypsum (PG), a white solid waste is a by-product generated from the wet process production of phosphoric acid [1] from base rock material Fluoroapatite $\mathrm{Ca}_{10} \mathrm{~F}_{2}$ $\left(\mathrm{PO}_{4}\right)_{6}$.

Phosphoric acid concentration and the reaction temperature determine the dominating crystal type, the amount of phosphoric acid that might be in access, the PG properties as well as the engineering properties. Three crystal types are normally formed namely; anhydrite, dihydrate and hemihydrate. The most common crystal type formed is dihydrate, $\mathrm{CaSO}_{4} \cdot 2 \mathrm{H}_{2} \mathrm{O}$ [2]. Water content between $7 \%$ to $9 \%$ and $\mathrm{pH}$ ranging from 2 to 5 , are commonly associated with PG. The material, unlike clay has low plasticity but can absorb water just like clay [2]. PG is normally discharged to the environment without any treatment resulting into environmental contamination and pollution of soil and water [3]. An estimated $100-280$ million tons of PG is generated worldwide per annum [4]. Due to the contaminants in the material and its radioactivity, there are limitations for reuse in other applications. Presently only a relatively little amount of PG is utilized for building and civil engineering applications due to the presence of radionuclides [5-10].
In a country like South Africa where waste PG is readily available and there is a great need for low cost housing due to the fast growing population, it is vital to investigate the potential use of the available waste material for low cost infrastructure development. Infrastructure development applications of residual PG will also solve the environmental pollution problems associated with this waste material. This study detailed the effect of chemical treatment on the radioactivity of $\mathrm{PG}$ and potential geotechnical engineering application.

\section{EXPERIMENTAL DETAILS}

Samples of PG were collected from a phosphoric acid manufacturing plant in the Phalaborwa, South Africa. The PG material was chemically treated with citric acid to reduce its radioactivity. The treated PG was then stabilized with calcium hydroxide, fly ash and basic oxygen furnace slag.

The PG samples were dried in an oven for $24 \mathrm{~h}$ at $50{ }^{\circ} \mathrm{C}$ prior conducting any test work. The dried sample was then pulverized to break the lumps. An Eriez Magnetic Rotary Riffle was used to divide the sample and obtain representative samples for characterization. Based on the previous studies conducted by [7, 11-13], a mild concentration of $0.5 \mathrm{M}$ citric acid was prepared and used as leaching reagent. Citric acid was added to PG at $40 \%$ solid loading. To conduct the leaching experiments a $20 \mathrm{~L}$ stirred tank containing the homogenous material of PG and citric acid was used. The mixture was placed in the tank at $25^{\circ} \mathrm{C}$, and agitated at $700 \mathrm{rpm}$ for $24 \mathrm{~h}$. After $24 \mathrm{~h}$ the thermostatic

\footnotetext{
* Corresponding author. Tel.: +27 115596527.

E-mail address: tmashifana@uj.ac.za (T.P. Mashifana)
} 
shaker was switched off, the samples were filtered, the solution stored for further characterization. The solids were dried in an oven at $50{ }^{\circ} \mathrm{C}$. To determine the elemental composition, the mineralogy, radioactivity and study the microstructure of PG before and after drying; the solid products were further analysed using X-ray diffraction spectrometer (XRD), X-ray fluorescence (XRF) and Scanning Electron Microscope. The determination of unconfined compressive strengths, the wet-dry cycles and soaking, atterberg and porosity test, followed, ASTM D698, ASTM D559-03, C37-14a, respectively. For toxicity leaching characteristic procedure (TLCP), the composites for treated PG and slag were miled after determining UCS and leached with an extraction buffer of acetic acid and sodium hydroxide $(\mathrm{pH} 4.93 \pm 0.05)$ at a liquid/solid ratio of 20:1 [14]. A thermostatic shaker was used for the extraction and the cured composites were subjected to 24 hours shaking at $25 \pm 2{ }^{\circ} \mathrm{C}$. After 24 hours the samples were filtered and the leachate was analysed using inductively Coupled Plasma-Optical Emission spectrometer (ICP-OES) to determine the concentration of leached heavy metals.

\subsection{PG-LFA Composite}

To determine the optimum mix of PG composite design that mobilized the highest unconfined compressive strength (UCS) and to investigate the optimum curing temperature, material composite designated TPG 30 was produced by blending $30 \%$ phosphogypsum (PG), $50 \%$ fly ash (FA) and $20 \%$ hydrated Lime (L). Material composite designated TPG 40 was a mixture of $40 \%$ PG, $40 \%$ FA and $20 \% \mathrm{~L}$, material composite TPG 50, contained $50 \%$ PG, $30 \%$ FA and $20 \% \mathrm{~L}$. The waste materials i.e. miled acid treated PG and FA were varied in the mix proportion and hydrated lime which is a commercial product was kept constant at a proportion of $20 \%$. All the material used for the test was dry. Fly ash and TPG were dried for 24 hours at $80{ }^{\circ} \mathrm{C}$ prior conducting the tests.

Table 1. Properties of unstabilised expansive soil

\begin{tabular}{|l|c|}
\hline \multicolumn{1}{|c|}{ Properties } & Expansive soil \\
\hline $\mathrm{pH}$ & 2.31 \\
\hline Density, $\mathrm{g} / \mathrm{cm}^{-3}$ & 2.55 \\
\hline Plastic limit, \% & 40 \\
\hline Liquid limit, \% & 58 \\
\hline Plastic index, \% & 18 \\
\hline UCS, MPa & 0.45 \\
\hline
\end{tabular}

The chemical compositions of the materials utilized to prepare the composites are presented in Table 2.

Table 2. Chemical composition of the raw material (wt \%)

\begin{tabular}{|l|c|c|c|c|}
\hline Composition & Raw PG & L & FA & $\begin{array}{c}\text { Treated } \\
\text { PG }\end{array}$ \\
\hline $\mathrm{F}$ & 1.063 & & & \\
\hline $\mathrm{Al}_{2} \mathrm{O}_{3}$ & 0.227 & 0.279 & 28.00 & 0.091 \\
\hline $\mathrm{SiO}_{2}$ & 1.370 & 0.503 & 47.90 & 0.857 \\
\hline $\mathrm{P}_{2} \mathrm{O}_{5}$ & 1.283 & 0.0288 & 0.725 & 0.719 \\
\hline $\mathrm{SO} 3$ & 51.01 & 0.191 & 0.606 & 54.4 \\
\hline $\mathrm{CaO}$ & 43.65 & 73.4 & 5.130 & 42.75 \\
\hline $\mathrm{TiO}_{2}$ & & & 2.470 & \\
\hline $\mathrm{Fe}_{2} \mathrm{O}_{3}$ & 0.121 & 0.225 & 4.830 & 0.048 \\
\hline $\begin{array}{l}\text { Total } \\
\text { radionuclides }\end{array}$ & 0.619 & & & 0.450 \\
\hline
\end{tabular}

\section{RESULTS AND DISCUSSION}

\subsection{Chemical composition of raw material}

The raw phosphogypsum as presented in Table 2 was laden mainly with sulphur trioxide, calcium oxide and radionuclides. After the chemical treatment radionuclides and other contaminants such as phosphorus and fluorides were significantly reduced. The hydrated lime utilized was dominated by calcium oxide. The fly ash consists of silica, aluminium oxide, calcium oxide, ferrous iron and titanium oxide. The high weight $\%$ of sulphate measured in both the raw and treated material may have a detrimental effect on the strength development of the material the presence of sulphate in some construction material lead to internal sulphate attack and strength loss [15]. Studies previously conducted by [16-18] dealt with the strength loss of cemented backfill due to sulphate attack. Sulphate attack also played a significant role in decreasing the durability of material by changing the chemical nature of the paste, and the mechanical properties.

\subsection{The effect of curing temperature on the strength of the composite}

Specimens were cast at the respective MDD and OMC at different mix proportions to determine the unconfined compressive strength (UCS) of each composite. The specimens were cured at low and high temperatures of $40{ }^{\circ} \mathrm{C}$ and $80{ }^{\circ} \mathrm{C}$ for 96 hours to determine the optimum curing temperature that mobilized the highest UCS and the result are presented in Fig. 1.

The maximum strength was mobilized by the composite with $30 \%$ PG content that were cured at both curing temperatures. The UCS obtained at $80{ }^{\circ} \mathrm{C}$ is higher that the $\mathrm{UCS}$ at $40^{\circ} \mathrm{C}$, thus temperature has a direct effect on the unconfined compressive strength of PG-L-FA composite. This is also indicates that the initial temperature increase accelerated pozzolanic or hydration reaction. The UCS improved from $0.45 \mathrm{MPa}$ to $1.2 \mathrm{MPa}$ at the lower temperature and from $0.45 \mathrm{MPa}$ to $1.5 \mathrm{MPa}$ at elevated temperature for PG content of $30 \%$. The major objective of the current study is high volume use of TPG. All the specimens with PG from 30-50\% exhibited strength improvement at high temperature. Although the PG content of $30 \%$ mobilized the highest UCS, the composites with PG of $50 \%$ were further investigated.

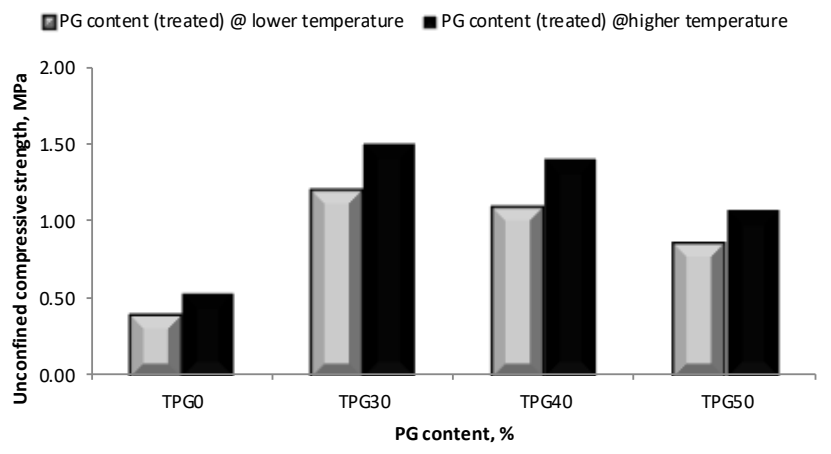

Fig. 1. UCS of the treated PG composites 


\subsection{The hydration process of TPG-FLA composites}

The reaction between Lime, fly ash, silica and alumina pozzolans formed strong cementitious bond. To study the mechanism that has occurred when treated PG was stabilised with lime and fly ash and subjected to elevated temperatures and to understand what influenced and contributed to the strength development at elevated temperature, a thorough study was conducted on the mineralogy of the composites to delineate the hydration products and the changes in the size of the discrete particle as a result of cementation and aggregation of particles.

After strength determination, the composites were further analysed and the results are presented in Fig. 2. The XRD analysis of the TPG 50 at an elevated temperature of $80^{\circ} \mathrm{C}$ is shown in Fig. 2.

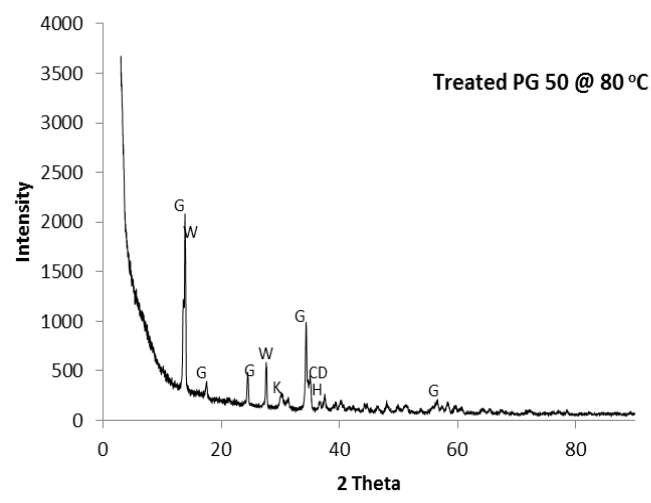

Fig. 2. XRD analysis of TPG 50 composite, [G]-Gypsum, [W]Wollastonite, $[\mathrm{H}]$-Hedenbergite, $[\mathrm{K}]$-Keatite, [CD]Calcium aluminium sulphate

The identified constituents are Gypsum (G), $\mathrm{CaSO}_{4} .2 \mathrm{H}_{2} \mathrm{O}(32.35 \%)$, calcium aluminium sulphate, $\mathrm{Ca}_{6} \mathrm{Al}_{2}\left(\mathrm{SO}_{4}\right)_{3}(\mathrm{OH}) 12 \cdot 26 \mathrm{H}_{2} \mathrm{O}$ (33.18), wollastonite (W), $\mathrm{CaSiO} 3(17.93 \%)$, hedenbergite $(\mathrm{H}), \mathrm{CaFeSi}_{2} \mathrm{O}_{6},(1.48 \%)$ and keatite $(\mathrm{K}), \mathrm{SiO}_{2}(15.01 \%)$. The new hydration products formed are, calcium aluminium sulphate, wollastonite and hedenbergite. There was a reduction in the gypsum content as compared to TPG prior curing; a reduction of $65 \%$ was indicated, due to the consumption of gypsum during the curing process. Due to the addition of fly ash, an increase of $87 \%$ silicate oxide was observed. No radionuclides were detected in the PG composite. Huang and Lin [19] in their study of the properties of phosphogypsum steel slag and granulated blast furnace slaglimestone cement composites reported an increase in peaks of ettringite and a decrease in PG due to the consumption of PG during hydration and formation of more ettringite.

\subsection{The effect of relative density on the geotechnical properties of stabilized TPG}

Fig. 3 illustrates the relative densities of unstabilised and stabilised TPG.

The PG material had a density of $2.31 \mathrm{~g} / \mathrm{cm}^{3}$ before stabilization. The density slightly decreased when stabilized, in addition, an increasing density trend with increment in TPG content was indicated. The lowest density was indicated by TPG 30 composite which mobilized the maximum strength of $1.5 \mathrm{MPa}$. Relative density is the most representative measure of the degree of compactness of soil [20]. The relative densities of soils fall between 2.5 for clays, 2.65 for silica beach sand and above 2.65 for $\mathrm{red} / \mathrm{brown}$ sand. These materials when compacted could be up to $1600 \mathrm{~kg} / \mathrm{m}^{3}$ and the material of such densities could mobilise UCS greater than $6 \mathrm{MPa}$ in most cases with lime and fly ash. Thus the low relative density accounted directly for the low MDD, porous inter granular packing and mobilized strength.

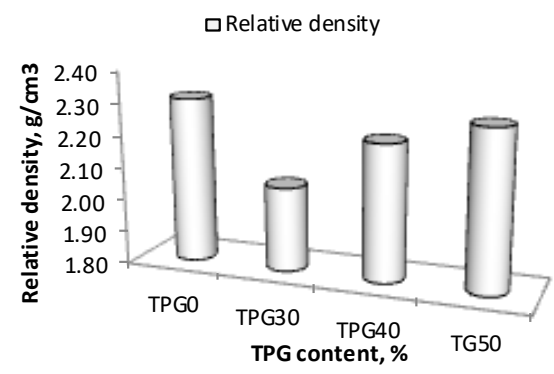

Fig. 3. Relative density of TPG mix designs before and after curing

\subsection{The effect of $\mathrm{pH}$ on the unconfined compressive strength}

The average $\mathrm{pH}$ measured for the unstabilised and stabilised TPG and its composites is presented in Table 3.

The $\mathrm{pH}$ shows that for the stabilised TPG, $\mathrm{pH}$ of the composites ranges from 10.53-12.72, presenting an alkaline material. Although unstabilised TPG material initially had an acidic pH of 2.31, the stabilization of TPG material with fly ash and lime and the curing of the specimens resulted in $\mathrm{pH}$ transformation of the composite material to an alkaline material. This is due the presence of hydroxide ion from the lime which contributed to the alkalinity of the material. Lime stabilization caused a significant improvement in soil texture and structure by reducing plasticity and by providing pozzolanic strength gain [21]. Maintenance of high $\mathrm{pH}$ above 10 indicated sustained pozzolanic reaction over a long term resulting in long term strength gain [21].

Table 3. $\mathrm{pH}$ of TPG and TPG composites

\begin{tabular}{|l|c|}
\hline Material & $\mathrm{pH}$ \\
\hline Unstabilised TPG & 1.51 \\
\hline TPG 30 & 10.53 \\
\hline TPG 40 & 10.86 \\
\hline TPG 50 & 12.72 \\
\hline
\end{tabular}

\subsection{Particle size distribution of TPG}

A Malvern masterizer 2000 was used to study the difference in PSD by adding $2 \mathrm{~g}$ of the raw PG and 50\% PG composite into the machine. The obtained PSD data was transformed into its moments using equation 1 and 2 . The number density function was calculated from the volume based histogram vol\% $L_{i . .} . i$, indicates the size sub-range and the particle concentration ( $\mathrm{vol} \%$ ) were generated by laser diffraction. The volume shape factor $k_{v}$ equal to $\pi / 6$ was used [22].

$n(L) d L=\sum_{i} \frac{\text { vol\% }_{i} \times \operatorname{conc}(\text { vol })}{100} \cdot \frac{1}{k_{v} L^{-3}} ;$ 
$m_{j}=\int_{0}^{\infty} L^{j} n(L) d L$

The three moments (0th, 2nd and 3rd) are of special interest and are related to the total number, area and volume of solid per unit volume of suspension respectively [22].

The PSD for raw PG and 50\% PG composite is presented in Fig. 4.

There is a significant modal size shift in the PG 50 composite relative to unstabilised PG composite. A bimodal size shift to the right was observed, indicating a change in the proportion of the larger sized particles and enlargement of discrete particles through cementation. Nelson [23] also reported a strong dependence of strength on grain size and noted that smaller grain sizes were associated with greater strength of the composite. Well graded soils are generally denser than poorly graded or uniformly graded soils, they are more compact and mobilized greater confined (biaxial or triaxial) and unconfined strength. This partly explains the observed improvement of UCS results of stabilized PG 50 composite relative to the unstabilised treated PG composite.

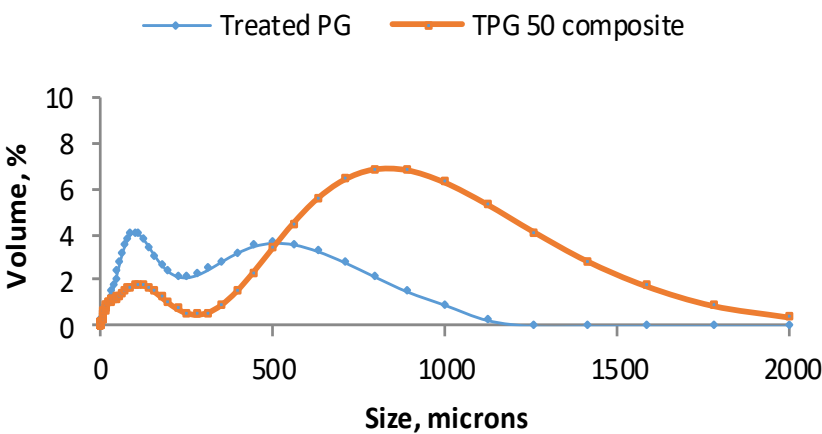

Fig. 4. PSD for unstabilised PG and stabilised PG 50 composite cured at $80^{\circ} \mathrm{C}$

\subsection{Moments of particle size of the composites}

The moments of PSD for unstabilised PG and stabilised PG composites was presented in Table 4.

Table 4. Moments of PSD of the treated PG and treated PG composites

\begin{tabular}{|l|c|c|c|}
\hline \multicolumn{1}{|c|}{ Composite } & $0^{\text {th }}\left(\# \mathrm{~m}^{-3} \cdot 10^{13}\right)$ & $2^{\text {nd }}\left(\mathrm{m}^{2} \mathrm{~m}^{-3} \cdot 10^{3}\right)$ & $3^{\text {rd }} \mathrm{m}^{3} \cdot \mathrm{m}^{-3)}$ \\
\hline $\begin{array}{l}\text { Unstabilised } \\
\text { TPG }\end{array}$ & 19.01 & 2.96 & 0.13 \\
\hline TPG 30 & 9.71 & 2.74 & 0.33 \\
\hline TPG 40 & 218.30 & 3.38 & 0.12 \\
\hline TPG 50 & 273.86 & 4.00 & 0.15 \\
\hline
\end{tabular}

For unstabilised PG specimen the maximum UCS was obtained at PG 30, and the moments of PSD shows that this is the composite that yielded a significant decrease in the particle number. The decrease is attributed to aggregation. The number of particles constituting PG 40 and PG 50 composites increased drastically with the increase in the PG content, indicating that the existing particles broke into new smaller particles of varying sizes. The surface area increased for PG 40, and PG 50 composites. A decrease in the particle surface area of PG 30 composite is attributed to aggregation, whereby smaller particles are bonded together to form larger but few particles. The volume of particles remained almost the same for TPG 40 and TPG 50 composites and increased in TPG 30 indicating that growth also played a role in size enlargement.

From the moments of PSD, it is evident that particle size and particle surface area played a significant role on the unconfined compressive strength presented in Fig. 1.

\subsection{Effect of moulding water content on soaked UCS}

Fig. 5 shows the UCS of TPG 50 composite after 24 hours inundation. The highest UCS obtained for the TPG 50 composite is $1 \mathrm{MPa}$, at the highest water absorption of $26 \%$ and OMC of $15 \%$. These results are also not consistent and show that the TPG 50 composite can absorb higher amount of water and still mobilize significant strength. The percentage reduction in strength from dry UCS in relation to moulding water content and percentage absorption is erratic, composites with $30 \%$ moulding water content, mobilized a maximum UCS of $0.8 \mathrm{MPa}$ at optimum moisture absorption of $20 \%$. As revealed by the XRD results that the predominant constituents in TPG50 are that of gypsum, ettringite, quartz, calcite and wollastonite. Gypsum products hold a pre-dominant position in the construction space due to their excellent insulation property [24]. Gypsum regulated early hydration reactions to prevent flash setting, improve strength development, and reduce drying shrinkage.

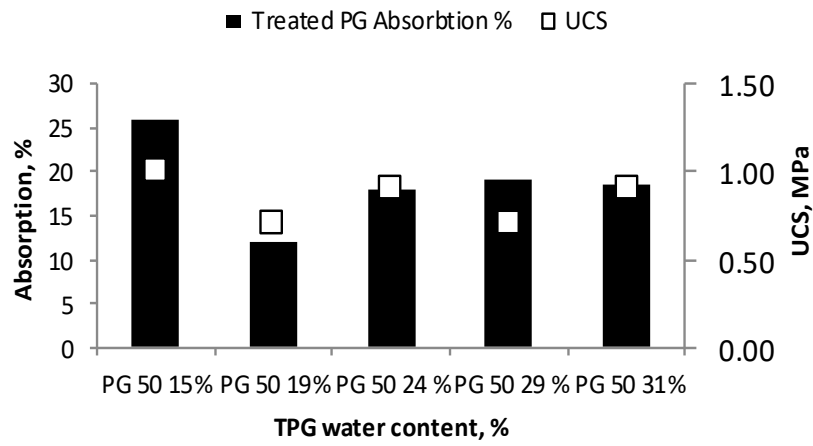

Fig. 5. UCS for TPG 50 after inundation

\subsection{Porosity of TPG 50 composite}

The porosity of TPG 50 composite is illustrated in Fig. 6. The lowest porosity is observed at PG 50 with the water content of $19 \%$. The PSD for this composite also revealed an increase in the volume of particles, resulting in the decrease in the porosity.

\subsection{Wet-dry cycles for PG 50 composite}

The durability of construction materials against wetting and drying climatic cycles is important because in most geotechnical applications, stabilized material are subjected to different moisture conditions as well as cycles of wetting and drying [25]. The PG 50 composite were subjected to 3 , 5, 7 and 10 cycles, and the effect on mobilized strengths were presented in Fig. 7. The maximum UCS was mobilized by PG 50 composite after wet-dry cycles of 10 days (5 cycles), Fig. 7. 


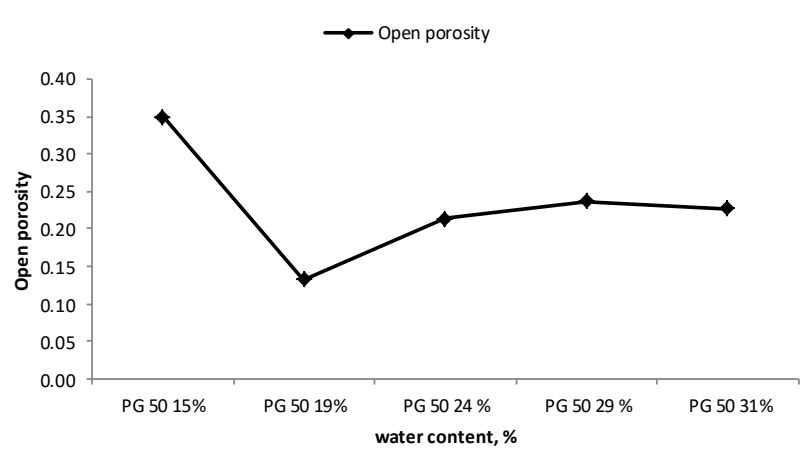

Fig. 6. Porosity of TPG 50 composites

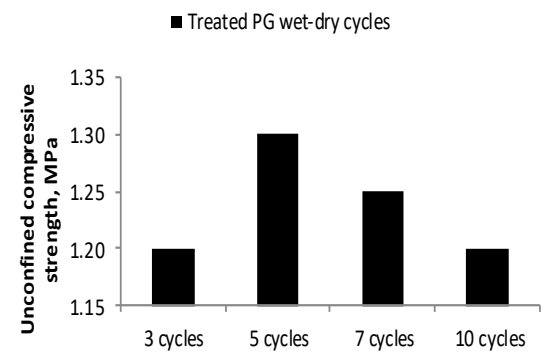

Fig. 7. UCS wet dry cycles for PG 50 composites

The maximum UCS mobilized was $1.3 \mathrm{MPa}$ and the results show that any increase in the cycles after that resulted in strength reduction. The average percentage water absorption was $28.71 \%$. Extended soaking cycles reflect extreme rainfall pattern in tropical and sub-tropical regions of the world. In comparison with dry UCS, Fig. 7 indicated that exposure of the PG 50 composite to sustained flooding does not result in significant strength degradation. The UCS obtained after 5 cycles show that the composites are moisture resistant. Thus, enhancing the potential use of lime and fly ash stabilized phosphogypsum for a number of field applications.

\subsection{SEM micrograph analysis}

Fig. 8 shows the surface microstructure of the unstabilised raw PG and PG 50 composite observed under scanning electron microscope.

The micro structure shows formation of finer particles that are smectite flakes with subhedral morphology. A rough surface is observed in both the unstabilised and stabilised PG looks bristly. This might be as the result of the new hydration products formed and covering the surface of the PG. The fine particles observed for the TPG 50 agree with the PSD analysis that showed an increase in the number of particles from unstabilised to stabilised PG. The overall SEM analysis of raw and treated PG composites supports the particle size distribution analysis results obtained and proved that number of particles, surface and volume of particles had a significant role in the higher unconfined compressive strengths. All the complexity of phosphogypsum originates from its crystal structure, which eventually influences its chemical behaviour [26]. The precipitation of attringite as small crystals rather than large clumps was responsible for the gain in strength due to filling up of pores. The study conducted by James and Pandian [27] postulated that more attringite with large clusters are formed when PG levels go beyond the optimal dosage, which may be responsible for the decrease in strength in the TPG 50 composite as compared to the highest strength obtained for TPG 30 .

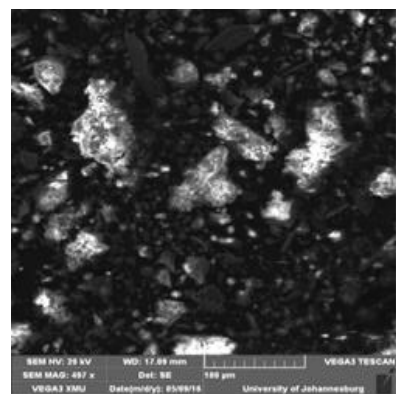

a

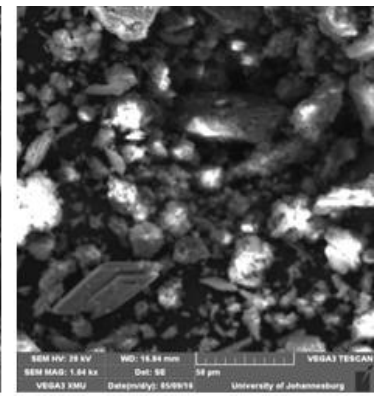

b
Fig. 8. SEM micrograph: $a$ - unstabilised TPG; $b$-stabilised TPG

\subsection{The effect of basic oxygen furnace slag on the strength of TPG 50}

Partial replacement of PG composite with slag for strength improvement investigated. Basic oxygen furnace slag (BOF slag) is an industrial waste product from steel manufacturing industry. The XRF analysis of BOF slag revealed that it is constituted of $31.31 \%$ calcium $(\mathrm{Ca})$, $19.91 \%$ iron $(\mathrm{Fe}), 6.6 \%$ silica $(\mathrm{Si})$ and $2.5 \%$ aluminium (Al). The BOF slag was added in proportions of $10 \%, 15 \%$, $30 \%, 40 \%$ and $50 \%$ in relation to the lime - fly ash binder content of the $50 \%$ PG-FAL composite. The composite was compacted to density of $1450 \mathrm{~kg} / \mathrm{m}^{3}$ and OMC of $31 \%$ and were cured for 96 hours at elevated temperature of $80^{\circ} \mathrm{C}$. The mobilized UCS results were presented in Fig. 9 .

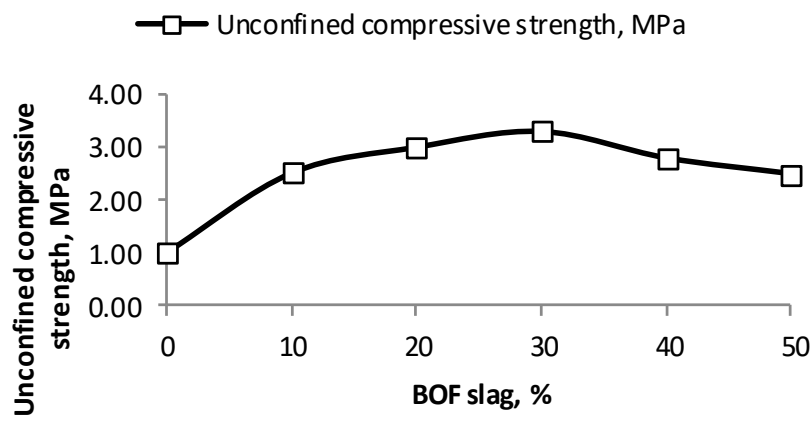

Fig. 9. Effect of BOF slag on the UCS of TPG 50 cured at elevated temperature

There was a drastic improvement on the UCS of TPG 50 composite with the inclusion of BOF slag in the PG-FA-Lime composite as indicated in Fig. 10. The strength improvement of over $100 \%$ is observed, from 1.08 (0 \% BOF slag) MPa to $3.2 \mathrm{MPa}$ (30\% BOF slag). Slag is widely used as aggregate in civil engineering construction and rail ballast but the main problem with using slag in civil engineering construction is the presence of free lime from the raw material and precipitated lime from molten slag [28]. BOF slag proved to be a suitable material/activator to further stabilize TPG and improve the UCS. The results demonstrate that further stabilization of TPG 50 is achievable with the inclusion of slag. 
Table 5. TLCP results for the TPG 50 and TPG 50-BOF composites (ppm)

\begin{tabular}{|l|c|c|c|c|c|c|c|c|c|c|c|c|c|c|}
\hline Element & $\mathrm{Al}$ & $\mathrm{As}$ & $\mathrm{Ba}$ & $\mathrm{Cd}$ & $\mathrm{Co}$ & $\mathrm{Ce}$ & $\mathrm{Cu}$ & $\mathrm{Fe}$ & $\mathrm{K}$ & $\mathrm{Ni}$ & $\mathrm{P}$ & $\mathrm{Pb}$ & $\mathrm{Tl}$ & $\mathrm{Zn}$ \\
\hline $\begin{array}{l}\text { TP 50 } \\
\text { composite }\end{array}$ & 6.585 & 0.051 & 0.036 & 0.003 & 0.009 & 0.118 & 0.007 & 4.89 & 22.76 & 0.01 & 0.387 & 0.003 & 0.091 & 0.005 \\
$\begin{array}{l}\text { TP 50- } \\
\text { slag } \\
\text { composite }\end{array}$ & 0.368 & 0.081 & 0.269 & 0.002 & 0.015 & 0.099 & 0.004 & 0.43 & 86.3 & 0.01 & 0.211 & 0.004 & 0.086 & 0.006 \\
\hline
\end{tabular}

\subsection{The effect of basic oxygen furnace slag on the strength of TPG 50}

To study the impact of the developed products on the environment, the TPG 50 and TPG 50-BOF slag composites after curing were subjected to TLCP, a testing methodology used to determine if a material is characteristically hazardous. The results obtained are presented in Table 5. The TLCP results presented in Table 5 indicate minimal concentrations of contaminants. It is evident from the results that the treatment of PG with citric acid, stabilizing the material with LFA and slag produced a leachate with low concentrations of the heavy metal. Therefore, citric acid can be used to reduce the environmental pollution problems constituted by the waste phosphogypsum.

\section{CONCLUSIONS}

The chemical treatment of waste phosphogypsum using mild citric acid reduced the radionuclides in the material. The composites also had a reduced radioactivity and can be used in bulk for constructions without any limitations. The stabilization of mild acid treated PG with LFA improved the unconfined compressive strengths, liquid limit and plastic limit. The UCS of the PG was improved by partial binder replacement with adding BOF slag. The slag utilized was alkaline and played a major role in improving the strength as hydrations products contributing to strength development are formed at alkaline medium. Silica and calcium were determined as the predominant constituents that contributed to strength improvement when BOF slag was introduced. In respect to strength, the material produced from TPG 50 composites has equivalent strength values as $\mathrm{C} 4$ material and can be used as subgrade material. TP 50 composite containing optimum percentage slag of $30 \%$ has same values of unconfined compressive strength as the $\mathrm{C} 2$ material, which can be used as subbase material. The minimum UCS required for masonry bricks as stipulated by SANS 1215 [29] 3.0 is 3.0 MPa and TPG 50 with $30 \%$ BOF slag mobilized UCS of $3.2 \mathrm{MPa}$, thus adequate for masonry applications

\section{Acknowledgments}

The authors would like to thank the University of Johannesburg and National Research Foundation of South Africa for the financial support.

\section{REFERENCES}

1. Chuck, A.G. Preliminary Experience with the PCC ByProduct Gypsum, Texas Transportation Institute, Texas A \& M University, College Station, 1983.
2. Wong, C., Ho, M.K. The Performance of Cement-Stabilized Phosphogypsum as Base, State Highway 146, La Porte, Texas (No. DHT-11), 1988.

3. Degirmenci, N., Okucu, A., Turabi, A. Application of Phosphogypsum in Soil Stabilization Building and Environment 42 (9) 2007: pp. 3393-3398.

https://doi.org/10.1016/j.buildenv.2006.08.010

4. Tayibi, H., López-Delgado, A., Choura, M., Gascó, C., Navarro, N., Alguacil, F.J., López Gómez, F.A. Preliminary Studies of a Phosphogypsum Stabilisation Process using a Sulphur Polymer Matrix, 2009.

5. Singh, M. Influence of Blended Gypsum on the Properties of Portland Cement and Portland Slag Cement Cement and Concrete Research 30 (8) 2000: pp. 1185-1188. https://doi.org/10.1016/S0008-8846(00)00306-9

6. Altun, I.A., Sert, Y. Utilization of Weathered Phosphogypsum as Set Retarder in Portland Cement Cement and Concrete Research 34 (4) 2004: pp. $677-680$. https://doi.org/10.1016/j.cemconres.2003.10.017

7. Singh, M. Treating Waste Phosphogypsum for Cement and Plaster Manufacture Cement and Concrete Research 32 (7) 2002: pp. $1033-1038$. https://doi.org/10.1016/S0008-8846(02)00723-8

8. Kumar, S. Fly Ash-Lime-Phosphogypsum Cementitious Binder: A New Trend in Bricks Materials and Structures 33 (1) 2000: pp. 59-64. https://doi.org/10.1007/BF02481697

9. Singh, M., Garg, M. Cementitious Binder from Fly Ash and Other Industrial Wastes Cement and Concrete Research 29 (3) 1999: pp. 309-314. https://doi.org/10.1016/S0008-8846(98)00210-5

10. Verbeek, C.J.R., du Plessis, B.J.G.W. Density and Flexural Strength of Phosphogypsum-Polymer Composites Construction and Building Materials 19 (4) 2005: pp. 265-274. https://doi.org/10.1016/j.conbuildmat.2004.07.011

11. Santos, E.A., Ladeira, A.C. Recovery of Uranium from Mine Waste by Leaching with Carbonate-Based Reagents Environmental Science \& Technology 45 (8) 2011: pp. 3591-3597. https://doi.org/10.1021/es2002056

12. Fernandes, H.M., $\quad$ Veiga, L.H.S., $\quad$ Franklin, M.R., Prado, V.C.S., Taddei, J.F. Environmental Impact Assessment of Uranium Mining and Milling Facilities: A Study Case at the Poços de Caldas Uranium Mining and Milling Site, Brazil International Journal of Rock Mechanics and Mining Sciences and Geomechanics Abstracts 1 (33) 1996: pp. 41A-42A.

13. Merritt, R.C. The Extractive Metallurgy of Uranium, Colorado School of Mines Research Institute. In Library of Congress Catalog Card (No. 71-157076), 1997.

14. Anastasiadou, K., Christopoulos, K., Mousios, E., Gidarakos, E. Solidification/Stabilization of Fly and Bottom Ash from Medical Waste Incineration facility Journal of 
Hazardous Materials 207 2012: pp. 165-170. https://doi.org/10.1016/j.jhazmat.2011.05.027

15. Fall, M., Benzaazoua, M. Modeling the Effect of Sulphate on Strength Development of Paste Backfill and Binder Mixture Optimization Cement and Concrete Research 35 (2) 2005: pp. $301-314$. https://doi.org/10.1016/j.cemconres.2004.05.020

16. Archibald, J.F., $\quad$ DeGagne, D.O., $\quad$ Lausch, $\mathbf{P}$., De Souza, E.M. Ground Waste Glass as a Pozzolanic Consolidation Agent for Mine Backfill CIM Bulletin 88 (995) 1995: pp. 80-87.

17. Benzaazoua, M., Ouellet, J., Servant, S., Newman, P., Verburg, R. Cementitious Backfill with High Sulfur Content Physical, Chemical, and Mineralogical characterization Cement and Concrete Research 29 (5) 1999: pp. 719-725. https://doi.org/10.1016/S0008-8846(99)00023-X

18. Mitchell, R.J., Wong, B.C. Behaviour of Cemented Tailings Sands Canadian Geotechnical Journal 19 (3) 1982: pp. $289-295$. https://doi.org/10.1139/t82-035

19. Li, Y., Sun, Y. Preliminary Study on Combined-Alkali-Slag Paste Materials Cement and Concrete Research 30 (6), 2000: pp. $963-966$. https://doi.org/10.1016/S0008-8846(00)00269-6

20. Wright, G.S. Comparison of Maximum Density of Cohesionless Soils Determined Using Vibratory and Impact Compaction Methods 12th Panamerican conference on soil mechanics and geotechnical engineer 2003.

21. Little, D.N. Evaluation of Structural Properties of Lime Stabilized Soils and Aggregates. National Lime Association, 1999.
22. Ntuli, F., Lewis, A.E. Kinetic Modelling of Nickel Powder Precipitation by High-Pressure Hydrogen Reduction Chemical Engineering Science 64 (9) 2009: pp. $2202-2215$.

https://doi.org/10.1016/j.ces.2009.01.026

23. Nelson, R. Geologic Analysis of Naturally Fractured Reservoirs. Gulf Professional, 2001.

24. Sophia, M., Sakthieswaran, N. Gypsum as a Construction Material- A Review of Recent Developments International Journal for Innovative Research in Science \& Technology 2 (12) 2016: pp. 315-323.

25. Sivapullaiah, P.V., Moghal, A.A.B. Role of Gypsum in the Strength Development of Fly Ashes with Lime Journal of Materials in Civil Engineering 23 (2) 2010: pp. 197-206. https://doi.org/10.1061/(ASCE)MT.1943-5533.0000158

26. Rajković, M.B., Tošković, D.V. Phosphogypsum Surface Characterisation Using Scanning Electron Microscopy Acta Periodica Technologica (34) 2003: pp. 61-70.

27. James, J., Pandian, P.K. Effect of Phosphogypsum on Strength of Lime Stabilized Expansive Soil Gradevinar 66 (12) 2014: pp. 1109-1116.

28. Shih, P.H., Wu, Z.Z., Chiang, H.L. Characteristics of Bricks Made from Waste Steel Slag Waste Management 24 (10) 2004: pp. 1043-1047. https://doi.org/10.1016/j.wasman.2004.08.006

29. South African National Standards, SANS 1215 - Concrete Masonry Units, Standards South Africa, Pretoria, 2008. 